\title{
II. Psychiatry in Denmark in 1983
}

\author{
Tove AARKRoG," Bispbjerg Hospital, Copenhagen
}

During the decade that 1 have practised psychiatry in Denmark, the discipline has on the whole shown evidence of progress. But the outlook for psychiatrists to fulfil their potential has fluctuated. It seems to me that recently we have become less confident about our role and future.

During the period of economic expansion in the 1950s the potential of the discipline corresponded most closely to what was expected from it. For example, new psychiatric hospitals were built, psychiatric clinics were opened, and the psychopharmacological revolution occurred.

The 1960 Rehabilitation Law was one way of expressing the fact that even the psychiatrically ill could join the Danish work force. More patients responded to treatment and were discharged and returned to the community. Psychiatry was about to be considered an equal with other medical specialties, and psychiatric illness as no different to physical illness.

But things began to go sour. In the therapeutic communities that evolved, a certain fanaticism developed that led to a dogmatic, rigid approach to treatment. Subsequently, it became clear that many patients could not benefit from that form of treatment. We also became aware of the limitations of the newly-discovered tranquillizers and antidepressants. The 'revolving-door patient' maintained on drugs became commonplace. Enthusiasm for the new methods of treatment diminished.

Shortly thereafter, at the end of the 1960s, the student revolution broke out and with it arrived an anti-authoritarian and anti-psychiatric movement. Criticism has its place, but it went too far. Anti-psychiatry has since then established itself and commonly has its representatives among the staff of psychiatric hospitals. Nurses can actually choose in some of their courses in psychiatry between studies in psychiatry and anti-psychiatry! The argument that psychiatric illness did not exist was especially pronounced. It seemed that the only acceptable psychiatry was one that rejected traditional methods of diagnosis, the role of biological factors in aetiology, and the use of drugs.

The most difficult aspect for many Danish psychiatrists has not been the debate itself, but the doubts that we have felt about ourselves.

Meanwhile, research in psychiatry improved, and training in psychotherapy, especially its psychoanalytically-oriented forms, expanded. Both were strongly encouraged by the Danish Psychiatric Society. But we experienced a growing separation between the promising developments of our discipline and their practical application. Danish society wanted more open psychiatric institutions and mental health centres in the community. Although most psychiatrists were

- President of the Danish Psychiatric Society 1980-2. agreed about the detrimental effects of hospitalization, the wish to create community centres bore with it a denial of the needs of severely-ill patients for traditional hospital care. There was also a risk that hospital-engaged psychiatrists, who moved their services into the community, would not offer sufficient support to the much-needed work still to be done within the hospitals.

The late 1970s saw the onset of the economic recession. The 'ideology' to abolish hospital beds coincided neatly with a political need to economize. Slogans such as 'Integrate the psychiatric patient into the community' and 'Psychiatric care in and near to the patient's home' became tools for politicians to cut hospital budgets. The support that was to be given to the patient in his own community never materialized and the good intentions behind this form of care faded away. Rehabilitated patients were no longer needed in a society with high unemployment. Co-operation between the social services and the psychiatric hospitals was generally made difficult and complicated by the bureaucratization of the social service system. The laudable aim to democratize social services through shared decisionmaking and group responsibility led to stagnation and rigidity.

In the 1980s the recession has continued. New employment regulations in the hospital sector concerning such matters as redundancy, rest periods and longer vacationswhich the politicians have so generously agreed to-have ruined continuity of the relationship between patient and staff. The number of effective working hours has decreased considerably. The unions have steadily achieved greater power. They are now the dominant influential force in the current system, which has replaced the old hierarchy. Their demand for uniform work patterns to be used on each and every ward inhibits initiative and change.

In January 1982 an agreement was reached with junior hospital doctors which from many points of view is disastrous for our hospitals, hospitals that were once considered the world's best. This agreement is similar to others in fields outside the hospital sector. Danish society does not seem to have the insight to appreciate that work with patients demands forms of organization different to those in industry. The present situation makes milieu therapy difficult to initiate and apply, while individual psychotherapy is impossible because of poor continuity in the doctor-patient relationship.

Patients on hospital wards are very ill indeed. It is a vicious circle. Some of our patients at present reach the clinic from the social services, when these services can no longer cope with them. These patients are not motivated for psychiatric treatment; the problems are, in any event, not psychiatric. Many people are now afraid of the stigma 
suffered by patients who have been hospitalized and registered as psychiatric patients. They refuse to be given a psychiatric diagnosis and are anxious at the thought of undergoing drug treatment.

The fact that Danish society is now informed about the political abuse of psychiatry in the USSR has severely damaged the image of our profession. The knowledge that a diagnostic classification can be distorted for political reasons undermines the confidence there is in the conventional use of diagnostic methods; forced hospitalization on political grounds leads to a reduced understanding of the need for legitimate, compulsory admission. Psychiatric registration used as a means of control in the USSR undermines the appreciation of the importance of a psychiatric register for research purposes.

The picture in Denmark today is that of psychiatry making scientific progress but undergoing considerable problems in its clinical application. The public is poorly informed about what psychiatry has to offer. Instead, there is fear and mistrust of the profession. There are economic and organizational limits to how psychiatric care is being allowed to develop. Psychiatry is little respected as a science today. What can we psychiatrists do? Public education is obviously not enough. Some psychiatrists have concluded that Denmark has the psychiatry it deserves. However, it is my opinion that psychiatrists ought to act vigorously and specify the kind of profession they want to be part of. We must also take a stand against the Soviet misuse of psychiatry (as does the resolution passed by the Danish Psychiatric Society in 1982). We must strongly oppose improper psychiatry, wherever it occurs. Finally, we should describe our discipline positively - the types of patients we can help and our methods of treatment.

\section{Correspondence

$$
\text { Confidential references }
$$

Dear Sirs

Although it has many imperfections, the system of collecting confidential references from independent nominated referees has served our appointment system well. Unfortunately no matter how we regulate our postgraduate training schemes, the quality of future consultants in the NHS is determined by the advisory appointment committees.

The interview in which every member appears to be driven to ask questions which often elucidate no information relevant to the decision before them, is an unreliable instrument. It is all too easy to be impressed by a plausible but shallow person, and to overlook the merits of one whose gauche or shy performance fails to impress. The independent references add another dimension to the interview and should sharpen the discrimination of the committee.

In recent years I have been appalled to read references from senior and respected members of the profession extolling the virtues of some psychiatric paragon who seems as far removed from the confident, but ignorant, applicant who faces us that we assume it to be a case of mistaken identity. However, the consistency of the discrepancies between testimonial and applicant make it clear that many colleagues have abandoned honesty in the interest of the candidate getting the job or of themselves getting rid of the candidate.

Quite rarely, now when a reference is received in which some minor blemish of character or experience is admitted I sigh with relief at this vestige of honesty and take the reference seriously. Unfortunately I find that some members respond to anything less than an adulatory reference with a firm decision to reject the candidate.

It is sad that one should have to say that a reference should reflect the integrity of the writer as well as the qualities of the applicant. A balanced reference can be of inestimable value to the decision-making process and the success or failure of any consultant should reflect upon those who supported his appointment.

How can we secure the attainment of reliable references? Should College assessors be invited to comment on gross discrepancies? Should we take up references on referees or should we give up referees?

\section{Leicester Royal Infirmary}

SYDNEY BRANDON

Leicester

\section{Dynamic psychotherapy in the NHS}

\section{DEAR SIRS}

In his attempt to show that dynamic psychotherapy is cost-effective under the NHS, Dr Whyte (Bulletin, February $1983,7,29)$ starts by excluding the severely, the acutely and the chronically ill, who are the bread and butter of the Service. He would treat cheaply by devoting one or more hourly sessions every week, for months or even years, to those who do not need a nurse, social worker, psychologist, occupational therapist, radiologist, pathologist, pharmacist or even ambulance, portering or laundry service. Dr Whyte would not himself train the ordinary nurse, social worker or psychologist, but would give priority to the training of other psychotherapists who would somehow reach the ordinary NHS staff. I am frankly unable to understand this kind of 